\title{
Analysis of protein expression regulated by lumican in PANC-1 cells using shotgun proteomics
}

\author{
TETSUSHI YAMAMOTO, MITSUHIRO KUDO, WEI-XIA PENG and ZENYANAITO \\ Departments of Pathology and Integrative Oncological Pathology, Nippon Medical School, \\ Bunkyo-ku, Tokyo 113-8602, Japan
}

Received March 19, 2013; Accepted May 30, 2013

DOI: $10.3892 /$ or.2013.2612

\begin{abstract}
Lumican, a member of the class II small leucinerich proteoglycan family, regulates the assembly and diameter of collagen fibers in the extracellular matrix of various tissues. We previously reported that lumican expression in the stromal tissues of pancreatic ductal adenocarcinoma (PDAC) correlates with tumor invasion, and tends to correlate with poor prognosis. Lumican stimulates growth and inhibits the invasion of a PDAC cell line. In the present study, we performed a global shotgun proteomic analysis using lumican-overexpressing PANC-1 cells and lumican downregulated PANC-1 cells to identify candidate proteins that are regulated by lumican and related to cell growth and invasion in PDAC cells. A total of 448 proteins were identified from lumican-overexpressing PANC-1 and control cells. Additionally, 451 proteins were identified from lumican-downregulated PANC-1 cells and control cells. As a result of semi-quantification based on spectral counting, 174 differentially expressed proteins were identified by lumican upregulation, and 143 differentially expressed proteins were identified by lumican downregulation. The expression levels of 24 proteins, including apoptosis- and invasion-related proteins correlated with lumican expression levels. It is likely that the expression of these proteins is regulated by lumican, and that they are involved in apoptosis and invasion in PDAC. These findings suggest that lumican may be involved in cell growth and invasion through the regulation of these 24 proteins expressed in PDAC.
\end{abstract}

\section{Introduction}

Lumican is a member of the class II small leucine-rich proteoglycan (SLRP) family. Members of this family have relatively small molecular sizes, with core proteins of approximately $40 \mathrm{kDa}$, and possess 6-10 leucine-rich repeat units in

Correspondence to: Professor Zenya Naito, Departments of Pathology and Integrative Oncological Pathology, Nippon Medical School, 1-1-5 Sendagi, Bunkyo-ku, Tokyo 113-8602, Japan

E-mail: naito@nms.ac.jp

Key words: lumican, proteoglycan, proteomic analysis, pancreatic cancer the core protein $(1,2)$. Amino acid sequencing indicates that lumican has 4 potential sites for $N$-linked keratan sulfate (KS) or oligosaccharides $(3,4)$. Therefore, lumican includes a core protein, glycoprotein and proteoglycan forms due to glycosylation (5). Lumican is a secreted collagen-binding extracellular matrix protein of the cornea, dermis and tendon stroma, arterial wall, and intestinal submucosa (6-9). Corneal opacity, as well as skin and tendon fragility due to disorganized and loosely packed collagen fibers in lumican-null mice suggest that lumican plays an important role in collagen fibrillogenesis $(10,11)$.

Lumican was first reported as one of the major KS proteoglycans in the chicken cornea (12). In addition to the cornea, lumican expression has been reported in various human tissues, including malignant tumor tissues (5,13-27). Among the clinicopathological characteristics of pancreatic ductal adenocarcinoma (PDAC), the localization of lumican in the stromal tissue adjacent to cancer cells correlates with advanced cancer stage, retroperitoneal and duodenal invasion, and residual tumor, and tends to correlate with shorter survival (21). These reports suggest that lumican localized in the stromal tissue is secreted from cancer cells and affects cancer cells through an autocrine and paracrine mechanism. We previously reported that PANC-1 cells, one of the PDAC cell lines, secrete only $70-\mathrm{kDa}$ glycosylated lumican into the extracellular space. We also demonstrated that the secreted lumican stimulated cell growth through ERK activation and inhibited cell invasion and matrix metalloproteinase (MMP)-9 activation using lumicanoverexpressing PANC-1 cells and lumican-downregulated PANC-1 cells (28). However, the mechanism of how lumican affects cell growth and invasion remains unclear.

In the present study, we performed shotgun liquid chromatography (LC)/mass spectrometry (MS)-based global proteomic analysis using protein from lumican-overexpressing PANC-1 cells and lumican-downregulated PANC-1 cells to examine how lumican regulates cell growth and invasion in PDAC cells. We identified 24 candidate proteins that may play an important role in cell growth and invasion and could be regulated by lumican.

\section{Materials and methods}

Materials. The following materials were purchased from Wako Pure Chemical Industries (Osaka, Japan): urea, 3-(3-cholami- 
dopropyl) dimethylammonio-1-propanesulphonate (CHAPS), dithiothreitol (DTT), Tris (2-carboxyethyl) phosphine hydrochloride (TCEP) and iodoacetamide (IAA); Amicon Ultra $0.5-\mathrm{ml}$ 3K was from Millipore (Tokyo, Japan), and thiourea from Nacalai Tesque, Inc. (Kyoto, Japan). All other chemicals and reagents were purchased from Sigma Chemical Corp. (St. Louis, MO, USA).

PDAC cell line. PANC-1 cells were obtained from the Cell Resource Center for Biomedical Research, Institute of Development, Aging and Cancer, Tohoku University (Sendai, Japan).

Protein extraction of lumican-regulated PANC-1 cells. The lumican-overexpressing PANC-1 cells, lumican-downregulated PANC-1 cells, and control cell lines (Mock and NC, respectively) were prepared as previously described (28). The lumican-regulated PANC-1 cells were cultured at a density of $5 \times 10^{5}$ cells in a $100-\mathrm{mm}$ dish in RPMI-1640 medium with $10 \%$ fetal bovine serum (FBS) for $72 \mathrm{~h}$. Then, cells were solubilized in urea lysis buffer (7 M urea, $2 \mathrm{M}$ thiourea, 5\% CHAPS, $1 \%$ Triton X-100). Protein concentration was measured using the Bradford method.

In-solution trypsin digestion. A gel-free digestion approach was performed in accordance with the protocol described by Bluemlein and Ralser (29). In brief, $10 \mu \mathrm{g}$ of protein extract from each sample was reduced by addition of $45 \mathrm{mM}$ DTT and $20 \mathrm{mM}$ TCEP and was then alkylated using $100 \mathrm{mM}$ IAA. Following alkylation, samples were digested with Proteomics Grade Trypsin (Agilent Technologies, Inc., Santa Clara, CA, USA) at $37^{\circ} \mathrm{C}$ for $24 \mathrm{~h}$. Next, digests were evaporated in a vacuum concentrator centrifuge and the residue was resuspended in $0.1 \%$ trifluoroacetic acid/5\% acetonitrile. The digests were filtered through Amicon Ultra $0.5-\mathrm{ml} 3 \mathrm{~K}$ to remove undigested proteins and the flow-through was used in the following analyses.

LC-MS/MS analysis of protein identification. Approximately $2-\mu \mathrm{g}$ peptide samples were injected into a peptide L-trap column (Chemicals Evaluation and Research Institute, Tokyo, Japan) using an HTC PAL autosampler (CTC Analytics, Zwingen, Switzerland) and further separated through an Advance-nano UHPLC using a Reverse-Phase C18-column (Zaplous column $\alpha, 3-\mu$ m diameter gel particles and $100 \AA$ pore size, $0.1 \times 150 \mathrm{~mm}$; both from AMR, Inc., Tokyo, Japan). The mobile phase consisted of solution A $(0.1 \%$ formic acid in water) and solution B (acetonitrile). The column was developed at a flow rate of $500 \mathrm{nl} / \mathrm{min}$ with a concentration gradient of acetonitrile from 5 to $45 \%$ B over 120 min. Gradient-eluted peptides were analyzed using an amaZon ETD ion-trap mass spectrometer (Bruker Daltonics, Billerica, MA, USA). The results were acquired in a data-dependent manner in which MS/MS fragmentation was performed on the 10 most intense peaks of every full MS scan.

All MS/MS spectra data were searched against the SwissProt Homo sapiens database using Mascot (v2.3.01; Matrix Science, London, UK). The search criteria was set as follows: enzyme, trypsin; allowance of up to two missed cleavage peptides; mass tolerance $\pm 0.5 \mathrm{Da}$ and MS/MS

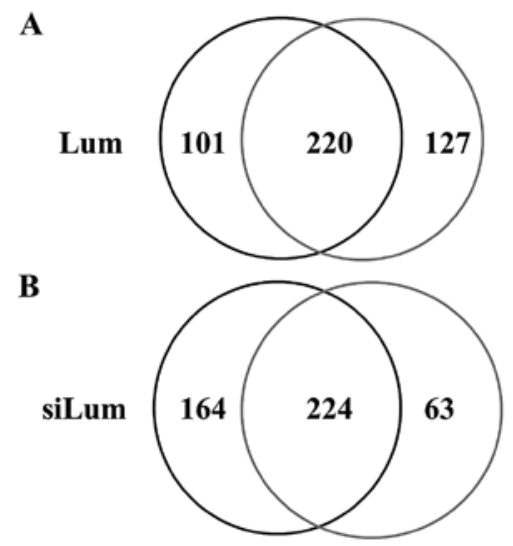

Figure 1. The Venn map of proteins identified from lumican-regulated PANC-1 cells. (A) In lumican-overexpressing PANC-1 cells (Lum), 321 proteins were identified and 347 were identified in control cells (Mock). (B) In lumican-downregulated PANC-1 cells (siLum), 388 proteins were identified and 287 were identifed in control cells (NC).

tolerance $\pm 0.5 \mathrm{Da}$; and modifications of cysteine carbamidomethylation and methionine oxidation.

Semi-quantitative analysis of identified proteins. The fold-changes in expressed proteins on the base 2 logarithmic scale were calculated using Rsc based upon spectral counting (30). Relative amounts of identified proteins were also calculated using the normalized spectral abundance factor (NSAF) (31). Differentially expressed proteins were chosen so that their Rsc satisfy $>1$ or $<-1$, which correspond to fold-changes of $>2$ or $<0.5$.

Bioinformatics. Functional annotations for the identified proteins whose expression level was regulated by lumican were processed using the Database for Annotation, Visualization and Integrated Discovery (DAVID), v6.7 (http://david.abcc. ncifcrf.gov/home.jsp) (32-34).

\section{Results}

Protein identification and profile in lumican-regulated PANC-1 cells. To examine the effect of lumican on cell growth and invasion of PDAC cells, we created two types of PANC-1 cells whose lumican expression level was regulated: lumican-overexpressing PANC-1 cells and lumican-downregulated PANC-1 cells (28). We then investigated the molecular profile of proteins whose expression level was regulated by lumican using shotgun proteomics. Fig. 1 shows the Venn map for the identified proteins in lumican-regulated PANC-1 cells. In lumican-overexpressing PANC-1 cells (Lum), 321 proteins were identified, and 347 were identified in control cells (Mock) under the search parameter settings used (Fig. 1A). On the other hand, 388 proteins were identified in lumicandownregulated PANC-1 cells (siLum) and 287 in control cells (NC) (Fig. 1B). Among the 448 proteins identified from lumican upregulated cells, 220 (49.1\%) proteins were identified in both cell lines, while $101(22.6 \%)$ and 127 (28.3\%) proteins were unique to Lum and Mock, respectively (Fig. 1A). Of the 451 total proteins identified from lumican downregulated 
A
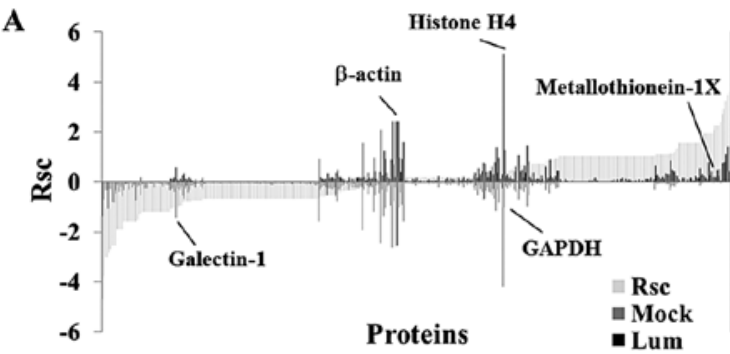

B

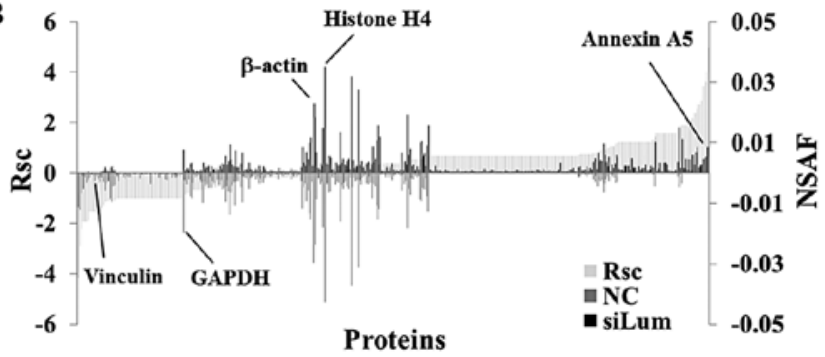

Figure 2. Semi-quantitative comparisons of the proteins identified in lumican-regulated PANC-1 cells. Rsc and normalized spectral abundance factor (NSAF) values were calculated for the proteins identified (X-axis). Protein expression was compared between (A) Lum vs. Mock and (B) siLum vs. control cells (NC). Proteins highly expressed in either Lum or Mock cells were to the right or left sides of the $\mathrm{X}$-axis. Housekeeping proteins were located near the center along the $\mathrm{X}$-axis.

cells, $224(49.7 \%)$ proteins were identified in both cell lines, whereas $164(36.3 \%)$ and $63(14.0 \%)$ proteins were unique to siLum and NC, respectively (Fig. 1B).

Semi-quantitative comparison of identified proteins in lumican-regulated PANC-1 cells. Next, we performed a label-free semi-quantitative method based on spectral counting, as described in the Materials and methods section, to find proteins whose expression levels were regulated by lumican. The Rsc value was plotted against the corresponding protein (X-axis) from left to right for proteins identified in the Lum and Mock groups (Fig. 2A). The positive and negative Rsc values indicate increased and decreased expression, respectively, in the Lum group. The NSAF value (bar) plotted against the corresponding protein (X-axis), NSAF of Lum (black bar) and Mock (gray bar) proteins are indicated above and below the X-axis, respectively (Fig. 2A). Proteins with either a high positive or negative Rsc value were considered candidate proteins whose expression level was regulated by lumican. Fig. 2B shows the Rsc and NSAF values of the siLum and $\mathrm{NC}$ groups as described above. In the lumican upregulated cells, the Rsc of metallothionein (MT)-1X was positive, and the Rsc of galectin-1 was negative (Fig. 2A). In the lumican downregulated cells, the Rsc of Annexin A5 was positive and the Rsc of vinculin was negative (Fig. 2B). Housekeeping proteins such as $\beta$-actin, histone $\mathrm{H} 4$ and GAPDH were located near the center of the $\mathrm{X}$-axis (Fig. 2).

As a result of semi-quantification, 174 differentially expressed proteins were identified in lumican upregulated PANC-1 cells (Table I), and a total of 143 differentially expressed proteins were identified in lumican downregulated PANC-1 cells (Table II). However, the expression level of housekeeping proteins such as $\beta$-actin, GAPDH and

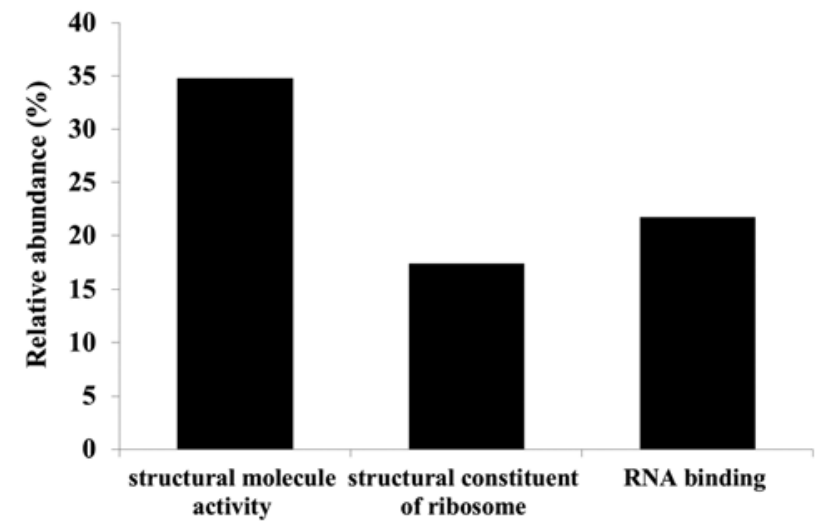

Figure 3. Analysis of identified proteins by gene ontology (GO) molecular function. Proteins assigned to a GO molecular function category; only significant categories $(\mathrm{P}<0.05)$ are shown.

histone $\mathrm{H} 4$ was not changed in lumican upregulated cells or lumican downregulated cells. In order to identify proteins whose expression levels were regulated by lumican, we selected proteins whose Rsc value was inversely associated between lumican upregulated cells and lumican downregulated cells. Twenty four proteins were identified as candidates (Table III).

Functional annotation of proteins whose expression level is regulated by lumican. Gene ontology (GO) analyses were performed using the identified candidate proteins for each molecular function (Fig. 3), biological process (Fig. 4) and cellular component (Fig. 5) using DAVID. We also analyzed pathway terms, but no significant category was found. Functional annotations were counted by normalizing to the total number of proteins identified. Since a multifunctional protein yields more than one annotation and some proteins are not defined by GO terms yet, the total number of classified proteins resulted in more or less than $100 \%$ (Fig. 3). Major $\mathrm{GO}$ molecular function categories of the identified proteins were $34.8 \%$ structural molecule activity, $17.4 \%$ structural constituents of ribosomes, and $21.7 \%$ RNA binding proteins (Fig. 3).

\section{Discussion}

In the present study, we used a gel-free LC-MS-based proteomics approach to examine the effect of lumican on cell growth and invasion. Using semi-quantitative methods based on spectral counting, we successfully identified several proteins whose expression levels were altered more than 2-fold in both lumican upregulated PANC-1 cells and lumican downregulated PANC-1 cells. A limitation of spectral counting is in its accurate quantitative capacity (35). Therefore, we selected candidate proteins whose expression level was regulated by lumican using the analysis results of two types of cells; lumican upregulated cells and lumican downregulated cells. Thus, we identified 24 proteins whose Rsc values were inversely correlated among differentially expressed proteins in lumican upregulated and downregulated cells as candidate proteins (Fig. 3). 
Table I. Differentially expressed proteins in lumican upregulated PANC-1 cells.

\begin{tabular}{|c|c|c|c|c|c|c|}
\hline \multirow[b]{2}{*}{ No. } & \multirow[b]{2}{*}{ ID } & \multirow[b]{2}{*}{ Accession no. and description } & \multirow[b]{2}{*}{$\begin{array}{c}\text { No. of } \\
\text { amino acids }\end{array}$} & \multicolumn{3}{|c|}{ Spectral counting } \\
\hline & & & & Mock & Lum & $\begin{array}{l}\text { Fold-change } \\
\text { (Rsc) }\end{array}$ \\
\hline 1 & ACTH_HUMAN & (P63267) Actin, $\gamma$-enteric smooth muscle & 376 & 35 & 0 & -4.69652 \\
\hline 2 & ACTC_HUMAN & (P68032) Actin, $\alpha$ cardiac muscle 1 & 377 & 18 & 0 & -3.7706617 \\
\hline 3 & TBB2A_HUMAN & (Q13885) Tubulin $\beta$-2A chain & 445 & 10 & 0 & -2.9897736 \\
\hline 4 & H2B1H_HUMAN & (Q93079) Histone H2B type 1-H & 126 & 9 & 0 & -2.8547299 \\
\hline 5 & HS904_HUMAN & (Q58FG1) Putative heat shock protein HSP 90- $\alpha$ A4 & 418 & 8 & 0 & -2.7058891 \\
\hline 6 & TBA4A_HUMAN & (P68366) Tubulin $\alpha-4 \mathrm{~A}$ chain & 448 & 8 & 0 & -2.7058891 \\
\hline 7 & H2AJ_HUMAN & (Q9BTM1) Histone H2A.J & 129 & 7 & 0 & -2.540088 \\
\hline 8 & H2B3B_HUMAN & (Q8N257) Histone H2B type 3-B & 126 & 7 & 0 & -2.540088 \\
\hline 9 & RLA0_HUMAN & (P05388) 60S acidic ribosomal protein P0 & 317 & 7 & 0 & -2.540088 \\
\hline 10 & H2B1O_HUMAN & (P23527) Histone H2B type 1-O & 126 & 4 & 0 & -1.885788 \\
\hline 11 & K2C71_HUMAN & (Q3SY84) Keratin, type II cytoskeletal 71 & 523 & 4 & 0 & -1.885788 \\
\hline 12 & NDKB_HUMAN & (P22392) Nucleoside diphosphate kinase B & 152 & 4 & 0 & -1.885788 \\
\hline 13 & RA1L2_HUMAN & (Q32P51) Heterogeneous nuclear ribonucleoprotein A1-like 2 & 320 & 4 & 0 & -1.885788 \\
\hline 14 & CH10_HUMAN & (P61604) $10 \mathrm{kDa}$ heat shock protein, mitochondrial & 102 & 4 & 0 & -1.885788 \\
\hline 15 & H2A1H_HUMAN & (Q96KK5) Histone H2A type 1-H & 128 & 3 & 0 & -1.5801931 \\
\hline 16 & HNRPK_HUMAN & (P61978) Heterogeneous nuclear ribonucleoprotein K & 463 & 3 & 0 & -1.5801931 \\
\hline 17 & K1C25_HUMAN & (Q7Z3Z0) Keratin, type I cytoskeletal 25 & 450 & 3 & 0 & -1.5801931 \\
\hline 18 & K22O_HUMAN & (Q01546) Keratin, type II cytoskeletal 2 oral & 638 & 3 & 0 & -1.5801931 \\
\hline 19 & MYL6_HUMAN & (P60660) Myosin light polypeptide 6 & 151 & 3 & 0 & -1.5801931 \\
\hline 20 & NFH_HUMAN & (P12036) Neurofilament heavy polypeptide & 1026 & 3 & 0 & -1.5801931 \\
\hline 21 & TAGL3_HUMAN & (Q9UI15) Transgelin-3 & 199 & 3 & 0 & -1.5801931 \\
\hline 22 & YI016_HUMAN & (A6NKZ8) Putative tubulin $\beta$ chain-like protein & 372 & 3 & 0 & -1.5801931 \\
\hline 23 & ANXA5_HUMAN & (P08758) Annexin A5 & 320 & 3 & 0 & -1.5801931 \\
\hline 24 & MT1G_HUMAN & (P13640) Metallothionein-1G & 62 & 3 & 0 & -1.5801931 \\
\hline 25 & K1C14_HUMAN & (P02533) Keratin, type I cytoskeletal 14 & 472 & 6 & 1 & -1.5040946 \\
\hline 26 & K2C80_HUMAN & (Q6KB66) Keratin, type II cytoskeletal 80 & 452 & 5 & 1 & -1.2892288 \\
\hline 27 & ACTBL_HUMAN & $(\mathrm{Q} 562 \mathrm{R} 1) \beta$-actin-like protein 2 & 376 & 13 & 4 & -1.259281 \\
\hline 28 & 1433B_HUMAN & (P31946) 14-3-3 protein $\beta / \alpha$ & 246 & 2 & 0 & -1.1924301 \\
\hline 29 & AINX_HUMAN & $(\mathrm{Q} 16352) \alpha$-internexin & 499 & 2 & 0 & -1.1924301 \\
\hline 30 & H2AZ_HUMAN & (H2AZ_HUMAN) Histone H2A.Z & 128 & 2 & 0 & -1.1924301 \\
\hline 31 & H2B1D_HUMAN & (P58876) Histone H2B type 1-D & 126 & 2 & 0 & -1.1924301 \\
\hline 32 & H2B1J_HUMAN & (P06899) Histone H2B type 1-J & 126 & 2 & 0 & -1.1924301 \\
\hline 33 & K1C13_HUMAN & (P13646) Keratin, type I cytoskeletal 13 & 458 & 2 & 0 & -1.1924301 \\
\hline 34 & K2C6C_HUMAN & (P48668) Keratin, type II cytoskeletal 6C & 564 & 2 & 0 & -1.1924301 \\
\hline 35 & KRT85_HUMAN & (P78386) Keratin, type II cuticular Hb5 & 507 & 2 & 0 & -1.1924301 \\
\hline 36 & MLL3_HUMAN & (Q8NEZ4) Histone-lysine N-methyltransferase MLL3 & 4911 & 2 & 0 & -1.1924301 \\
\hline 37 & NDK8_HUMAN & (O60361) Putative nucleoside diphosphate kinase & 137 & 2 & 0 & -1.1924301 \\
\hline 38 & NFM_HUMAN & (P07197) Neurofilament medium polypeptide & 916 & 2 & 0 & -1.1924301 \\
\hline 39 & SERPH_HUMAN & (P50454) Serpin H1 & 418 & 2 & 0 & -1.1924301 \\
\hline 40 & U17L5_HUMAN & (A8MUK1) Ubiquitin carboxyl-terminal hydrolase 17-like protein 5 & 530 & 2 & 0 & -1.1924301 \\
\hline 41 & URFB1_HUMAN & (Q6BDS2) UHRF1-binding protein 1 & 1440 & 2 & 0 & -1.1924301 \\
\hline 42 & MDHM_HUMAN & (P40926) Malate dehydrogenase, mitochondrial & 338 & 2 & 0 & -1.1924301 \\
\hline 43 & IF5A1_HUMAN & (P63241) Eukaryotic translation initiation factor 5A-1 & 154 & 2 & 0 & -1.1924301 \\
\hline 44 & SFPQ_HUMAN & (P23246) Splicing factor, proline- and glutamine-rich & 707 & 2 & 0 & -1.1924301 \\
\hline 45 & NACA_HUMAN & (Q13765) Nascent polypeptide-associated complex subunit $\alpha$ & 215 & 2 & 0 & -1.1924301 \\
\hline 46 & EF1B_HUMAN & (P24534) Elongation factor $1-\beta$ & 225 & 2 & 0 & -1.1924301 \\
\hline 47 & RS4X_HUMAN & (P62701) 40S ribosomal protein $\mathrm{S} 4, \mathrm{X}$ isoform & 263 & 2 & 0 & -1.1924301 \\
\hline 48 & IF4A2_HUMAN & (Q14240) Eukaryotic initiation factor 4A-II & 407 & 9 & 3 & -1.0866682 \\
\hline 49 & EF2_HUMAN & (P13639) Elongation factor 2 & 858 & 16 & 6 & -1.0697973 \\
\hline 50 & HSP72_HUMAN & (P54652) Heat shock-related $70 \mathrm{kDa}$ protein 2 & 639 & 11 & 4 & -1.0396137 \\
\hline
\end{tabular}


Table I. Continued.

\begin{tabular}{|c|c|c|c|c|c|c|}
\hline \multirow[b]{2}{*}{ No. } & \multirow[b]{2}{*}{ ID } & \multirow[b]{2}{*}{ Accession no. and description } & \multirow[b]{2}{*}{$\begin{array}{l}\text { No. of } \\
\text { amino acids }\end{array}$} & \multicolumn{3}{|c|}{ Spectral counting } \\
\hline & & & & Mock & Lum & $\begin{array}{l}\text { Fold-change } \\
\qquad(\mathrm{Rsc})\end{array}$ \\
\hline 51 & DESM_HUMAN & (P17661) Desmin & 470 & 13 & 5 & -1.0068984 \\
\hline 52 & LEG1_HUMAN & (P09382) Galectin-1 & 135 & 13 & 5 & -1.0068984 \\
\hline 53 & CC113_HUMAN & (Q9H0I3) Coiled-coil domain-containing protein 113 & 377 & 0 & 1 & 1.03639903 \\
\hline 54 & H11_HUMAN & (Q02539) Histone H1.1 & 215 & 0 & 1 & 1.03639903 \\
\hline 55 & UBA1_HUMAN & (P22314) Ubiquitin-like modifier-activating enzyme 1 & 1058 & 0 & 1 & 1.03639903 \\
\hline 56 & TCPH_HUMAN & (Q99832) T-complex protein 1 subunit eta & 543 & 0 & 1 & 1.03639903 \\
\hline 57 & RL31_HUMAN & (P62899) 60S ribosomal protein L31 & 125 & 0 & 1 & 1.03639903 \\
\hline 58 & ADT4_HUMAN & (Q9H0C2) ADP/ATP translocase 4 & 315 & 0 & 1 & 1.03639903 \\
\hline 59 & BRE1B_HUMAN & (O75150) E3 ubiquitin-protein ligase BRE1B & 1001 & 0 & 1 & 1.03639903 \\
\hline 60 & CALX_HUMAN & (P27824) Calnexin & 592 & 0 & 1 & 1.03639903 \\
\hline 61 & CAP1_HUMAN & (Q01518) Adenylyl cyclase-associated protein 1 & 475 & 0 & 1 & 1.03639903 \\
\hline 62 & CAZA1_HUMAN & (P52907) F-actin-capping protein subunit $\alpha-1$ & 286 & 0 & 1 & 1.03639903 \\
\hline 63 & CCNT1_HUMAN & (O60563) Cyclin-T1 & 726 & 0 & 1 & 1.03639903 \\
\hline 64 & CGNL1_HUMAN & (Q0VF96) Cingulin-like protein 1 & 1302 & 0 & 1 & 1.03639903 \\
\hline 65 & CISY_HUMAN & (O75390) Citrate synthase, mitochondrial & 466 & 0 & 1 & 1.03639903 \\
\hline 66 & CLIP1_HUMAN & (P30622) CAP-Gly domain-containing linker protein 1 & 1438 & 0 & 1 & 1.03639903 \\
\hline 67 & CN37_HUMAN & (P09543) 2',3'-cyclic-nucleotide 3'-phosphodiesterase & 421 & 0 & 1 & 1.03639903 \\
\hline 68 & CTSR1_HUMAN & (Q8NEC5) Cation channel sperm-associated protein 1 & 780 & 0 & 1 & 1.03639903 \\
\hline 69 & CX057_HUMAN & (Q6NSI4) Uncharacterized protein CXorf57 & 855 & 0 & 1 & 1.03639903 \\
\hline 70 & DDX21_HUMAN & (Q9NR30) Nucleolar RNA helicase 2 & 783 & 0 & 1 & 1.03639903 \\
\hline 71 & DYXC1_HUMAN & (Q8WXU2) Dyslexia susceptibility 1 candidate gene 1 protein & 420 & 0 & 1 & 1.03639903 \\
\hline 72 & EFTU_HUMAN & (P49411) Elongation factor Tu, mitochondrial & 452 & 0 & 1 & 1.03639903 \\
\hline 73 & EHD1_HUMAN & (Q9H4M9) EH domain-containing protein 1 & 534 & 0 & 1 & 1.03639903 \\
\hline 74 & EIF3H_HUMAN & (O15372) Eukaryotic translation initiation factor 3 subunit $\mathrm{H}$ & 352 & 0 & 1 & 1.03639903 \\
\hline 75 & EHD1_HUMAN & (Q9H4M9) EH domain-containing protein 1 & 534 & 0 & 1 & 1.03639903 \\
\hline 76 & FETUA_HUMAN & (P02765) $\alpha$-2-HS-glycoprotein & 367 & 0 & 1 & 1.03639903 \\
\hline 77 & HIP1R_HUMAN & (O75146) Huntingtin-interacting protein 1-related protein & 1068 & 0 & 1 & 1.03639903 \\
\hline 78 & HMGN1_HUMAN & (P05114) Non-histone chromosomal protein HMG-14 & 100 & 0 & 1 & 1.03639903 \\
\hline 79 & HMGN4_HUMAN & $\begin{array}{l}\text { (O00479) High mobility group nucleosome-binding domain- } \\
\text { containing protein } 4\end{array}$ & 90 & 0 & 1 & 1.03639903 \\
\hline 80 & HNRH3_HUMAN & (P31942) Heterogeneous nuclear ribonucleoprotein H3 & 346 & 0 & 1 & 1.03639903 \\
\hline 81 & IDE_HUMAN & (P14735) Insulin-degrading enzyme & 1019 & 0 & 1 & 1.03639903 \\
\hline 82 & IMA2_HUMAN & (P52292) Importin subunit $\alpha-2$ & 529 & 0 & 1 & 1.03639903 \\
\hline 83 & IMDH2_HUMAN & (P12268) Inosine-5'-monophosphate dehydrogenase 2 & 514 & 0 & 1 & 1.03639903 \\
\hline 84 & K1C26_HUMAN & (Q7Z3Y9) Keratin, type I cytoskeletal 26 & 468 & 0 & 1 & 1.03639903 \\
\hline 85 & K6PL_HUMAN & (P17858) 6-phosphofructokinase, liver type & 780 & 0 & 1 & 1.03639903 \\
\hline 86 & MYH11_HUMAN & (P35749) Myosin-11 & 1972 & 0 & 1 & 1.03639903 \\
\hline 87 & MYH14_HUMAN & (Q7Z406) Myosin-14 & 1995 & 0 & 1 & 1.03639903 \\
\hline 88 & PAR10_HUMAN & (Q53GL7) Poly [ADP-ribose] polymerase 10 & 1025 & 0 & 1 & 1.03639903 \\
\hline 89 & PI3R4_HUMAN & (Q99570) Phosphoinositide 3-kinase regulatory subunit 4 & 1358 & 0 & 1 & 1.03639903 \\
\hline 90 & PRDX4_HUMAN & (Q13162) Peroxiredoxin-4 & 271 & 0 & 1 & 1.03639903 \\
\hline 91 & PRS6A_HUMAN & (P17980) 26S protease regulatory subunit 6A & 439 & 0 & 1 & 1.03639903 \\
\hline 92 & PSB3_HUMAN & (P49720) Proteasome subunit $\beta$ type-3 & 205 & 0 & 1 & 1.03639903 \\
\hline 93 & PTN22_HUMAN & (Q9Y2R2) Tyrosine-protein phosphatase non-receptor type 22 & 807 & 0 & 1 & 1.03639903 \\
\hline 94 & RAB10_HUMAN & (P61026) Ras-related protein Rab-10 & 200 & 0 & 1 & 1.03639903 \\
\hline 95 & RBBP7_HUMAN & (Q16576) Histone-binding protein RBBP7 & 425 & 0 & 1 & 1.03639903 \\
\hline 96 & RL18A_HUMAN & (Q02543) 60S ribosomal protein L18a & 176 & 0 & 1 & 1.03639903 \\
\hline 97 & RL27A_HUMAN & (P46776) 60S ribosomal protein L27a & 148 & 0 & 1 & 1.03639903 \\
\hline 98 & RL34_HUMAN & (P49207) 60S ribosomal protein L34 & 117 & 0 & 1 & 1.03639903 \\
\hline 99 & RL3L_HUMAN & (Q92901) 60S ribosomal protein L3-like & 407 & 0 & 1 & 1.03639903 \\
\hline 100 & RL40_HUMAN & (P62987) Ubiquitin-60S ribosomal protein L40 & 128 & 0 & 1 & 1.03639903 \\
\hline
\end{tabular}


Table I. Continued.

\begin{tabular}{|c|c|c|c|c|c|c|}
\hline \multirow[b]{2}{*}{ No. } & \multirow[b]{2}{*}{ ID } & \multirow[b]{2}{*}{ Accession no. and description } & \multirow[b]{2}{*}{$\begin{array}{c}\text { No. of } \\
\text { amino acids }\end{array}$} & \multicolumn{3}{|c|}{ Spectral counting } \\
\hline & & & & Mock & Lum & $\begin{array}{l}\text { Fold-change } \\
\text { (Rsc) }\end{array}$ \\
\hline 101 & ROAA_HUMAN & (Q99729) Heterogeneous nuclear ribonucleoprotein A/B & 332 & 0 & 1 & 1.03639903 \\
\hline 102 & SET_HUMAN & (Q01105) Protein SET & 290 & 0 & 1 & 1.03639903 \\
\hline 103 & SODC_HUMAN & (P00441) Superoxide dismutase [Cu-Zn] & 154 & 0 & 1 & 1.03639903 \\
\hline 104 & SPSY_HUMAN & (P52788) Spermine synthase & 366 & 0 & 1 & 1.03639903 \\
\hline 105 & SYRC_HUMAN & (P54136) Arginyl-tRNA synthetase, cytoplasmic & 660 & 0 & 1 & 1.03639903 \\
\hline 106 & TADBP_HUMAN & (Q13148) TAR DNA-binding protein 43 & 414 & 0 & 1 & 1.03639903 \\
\hline 107 & TALDO_HUMAN & (P37837) Transaldolase & 337 & 0 & 1 & 1.03639903 \\
\hline 108 & TECT2_HUMAN & (Q96GX1) Tectonic-2 & 697 & 0 & 1 & 1.03639903 \\
\hline 109 & TEBP_HUMAN & (Q15185) Prostaglandin E synthase 3 & 160 & 0 & 1 & 1.03639903 \\
\hline 110 & TPD54_HUMAN & (O43399) Tumor protein D54 & 206 & 0 & 1 & 1.03639903 \\
\hline 111 & UGPA_HUMAN & (Q16851) UTP - glucose-1-phosphate uridylyltransferase & 508 & 0 & 1 & 1.03639903 \\
\hline 112 & WDR53_HUMAN & (Q7Z5U6) WD repeat-containing protein 53 & 358 & 0 & 1 & 1.03639903 \\
\hline 113 & ZC12A_HUMAN & (Q5D1E8) Ribonuclease ZC3H12A & 599 & 0 & 1 & 1.03639903 \\
\hline 114 & RL22_HUMAN & (P35268) 60S ribosomal protein L22 & 128 & 0 & 1 & 1.03639903 \\
\hline 115 & RL13_HUMAN & (P26373) 60S ribosomal protein L13 & 211 & 0 & 1 & 1.03639903 \\
\hline 116 & RL23_HUMAN & (P62829) 60S ribosomal protein $\mathrm{L} 23$ & 140 & 0 & 1 & 1.03639903 \\
\hline 117 & RS11_HUMAN & (P62280) 40S ribosomal protein S11 & 158 & 0 & 1 & 1.03639903 \\
\hline 118 & SUMO2_HUMAN & (P61956) Small ubiquitin-related modifier 2 & 95 & 0 & 1 & 1.03639903 \\
\hline 119 & TFR1_HUMAN & (P02786) Transferrin receptor protein 1 & 760 & 0 & 1 & 1.03639903 \\
\hline 120 & RL11_HUMAN & (P62913) 60S ribosomal protein L11 & 178 & 0 & 1 & 1.03639903 \\
\hline 121 & EF1A2_HUMAN & (Q05639) Elongation factor 1- $\alpha 2$ & 463 & 10 & 19 & 1.04422777 \\
\hline 122 & CBX1_HUMAN & (P83916) Chromobox protein homolog 1 & 185 & 1 & 3 & 1.10688593 \\
\hline 123 & RL12_HUMAN & (P30050) 60S ribosomal protein L12 & 165 & 1 & 3 & 1.10688593 \\
\hline 124 & RAN_HUMAN & (P62826) GTP-binding nuclear protein Ran & 216 & 1 & 3 & 1.10688593 \\
\hline 125 & PDIA6_HUMAN & (Q15084) Protein disulfide-isomerase A6 & 440 & 1 & 3 & 1.10688593 \\
\hline 126 & RL10L_HUMAN & (Q96L21) 60S ribosomal protein L10-like & 214 & 1 & 3 & 1.10688593 \\
\hline 127 & SRC8_HUMAN & (Q14247) Src substrate cortactin & 550 & 1 & 3 & 1.10688593 \\
\hline 128 & RL8_HUMAN & (P62917) 60S ribosomal protein L8 & 257 & 1 & 3 & 1.10688593 \\
\hline 129 & RS23_HUMAN & (P62266) 40S ribosomal protein S23 & 143 & 1 & 3 & 1.10688593 \\
\hline 130 & RS13_HUMAN & (P62277) 40S ribosomal protein $\mathrm{S} 13$ & 151 & 1 & 3 & 1.10688593 \\
\hline 131 & RL24_HUMAN & (P83731) 60S ribosomal protein L24 & 157 & 1 & 3 & 1.10688593 \\
\hline 132 & RL37A_HUMAN & (P61513) 60S ribosomal protein $\mathrm{L} 37 \mathrm{a}$ & 92 & 2 & 5 & 1.13371212 \\
\hline 133 & PAL4A_HUMAN & (Q9Y536) Peptidylprolyl cis-trans isomerase A-like 4A/B/C & 164 & 2 & 5 & 1.13371212 \\
\hline 134 & RL18_HUMAN & (Q07020) 60S ribosomal protein L18 & 188 & 2 & 5 & 1.13371212 \\
\hline 135 & K1C9_HUMAN & (P35527) Keratin, type I cytoskeletal 9 & 623 & 8 & 17 & 1.17638585 \\
\hline 136 & TBB1_HUMAN & (Q9H4B7) Tubulin $\beta-1$ chain & 451 & 3 & 8 & 1.31408061 \\
\hline 137 & PAIRB_HUMAN & (Q8NC51) Plasminogen activator inhibitor 1 RNA-binding protein & 408 & 2 & 6 & 1.34868122 \\
\hline 138 & CATD_HUMAN & (P07339) Cathepsin D & 412 & 0 & 2 & 1.56775608 \\
\hline 139 & FLNB_HUMAN & (O75369) Filamin-B & 2602 & 0 & 2 & 1.56775608 \\
\hline 140 & MYL6B_HUMAN & (P14649) Myosin light chain 6B & 208 & 0 & 2 & 1.56775608 \\
\hline 141 & PSB2_HUMAN & (P49721) Proteasome subunit $\beta$ type- 2 & 201 & 0 & 2 & 1.56775608 \\
\hline 142 & RS7_HUMAN & (P62081) 40S ribosomal protein S7 & 194 & 0 & 2 & 1.56775608 \\
\hline 143 & IQGA1_HUMAN & (P46940) Ras GTPase-activating-like protein IQGAP1 & 1657 & 0 & 2 & 1.56775608 \\
\hline 144 & DX39B_HUMAN & (Q13838) Spliceosome RNA helicase DDX39B & 428 & 0 & 2 & 1.56775608 \\
\hline 145 & GANAB_HUMAN & (Q9BS14)Neutral $\alpha$-glucosidase AB & 944 & 0 & 2 & 1.56775608 \\
\hline 146 & H13_HUMAN & (P16402) Histone H1.3 & 221 & 0 & 2 & 1.56775608 \\
\hline 147 & H14_HUMAN & (P10412) Histone H1.4 & 219 & 0 & 2 & 1.56775608 \\
\hline 148 & HNRH2_HUMAN & (P55795) Heterogeneous nuclear ribonucleoprotein $\mathrm{H} 2$ & 449 & 0 & 2 & 1.56775608 \\
\hline 149 & ATPA_HUMAN & (P25705) ATP synthase subunit $\alpha$, mitochondrial & 553 & 0 & 2 & 1.56775608 \\
\hline 150 & H31T_HUMAN & (Q16695) Histone H3.1t & 136 & 0 & 2 & 1.56775608 \\
\hline
\end{tabular}


Table I. Continued.

\begin{tabular}{|c|c|c|c|c|c|c|}
\hline \multirow[b]{2}{*}{ No. } & \multirow[b]{2}{*}{ ID } & \multirow[b]{2}{*}{ Accession no. and description } & \multirow[b]{2}{*}{$\begin{array}{c}\text { No. of } \\
\text { amino acids }\end{array}$} & \multicolumn{3}{|c|}{ Spectral counting } \\
\hline & & & & Mock & Lum & $\begin{array}{l}\text { Fold-change } \\
\text { (Rsc) }\end{array}$ \\
\hline 151 & RL10A_HUMAN & (P62906) 60S ribosomal protein L10a & 217 & 0 & 2 & 1.56775608 \\
\hline 152 & H12_HUMAN & (P16403) Histone H1.2 & 213 & 0 & 2 & 1.56775608 \\
\hline 153 & TBB8_HUMAN & (Q3ZCM7) Tubulin $\beta-8$ chain & 444 & 5 & 15 & 1.57505162 \\
\hline 154 & EF1D_HUMAN & (P29692) Elongation factor $1-\delta$ & 281 & 1 & 5 & 1.6649664 \\
\hline 155 & RLA0L_HUMAN & (Q8NHW5) 60S acidic ribosomal protein P0-like & 317 & 1 & 6 & 1.8799355 \\
\hline 156 & RS8_HUMAN & (P62241) 40S ribosomal protein S8 & 208 & 0 & 3 & 1.95562202 \\
\hline 157 & CCD50_HUMAN & (Q8IVM0) Coiled-coil domain-containing protein 50 & 306 & 0 & 3 & 1.95562202 \\
\hline 158 & K2C6A_HUMAN & (P02538) Keratin, type II cytoskeletal 6A & 564 & 0 & 3 & 1.95562202 \\
\hline 159 & MT1X_HUMAN & (P80297) Metallothionein-1X & 61 & 0 & 3 & 1.95562202 \\
\hline 160 & RL17_HUMAN & (P18621) 60S ribosomal protein L17 & 184 & 0 & 3 & 1.95562202 \\
\hline 161 & RS26_HUMAN & (P62854) 40S ribosomal protein S26 & 115 & 0 & 3 & 1.95562202 \\
\hline 162 & H15_HUMAN & (P16401) Histone H1.5 & 226 & 0 & 3 & 1.95562202 \\
\hline 163 & ATPB_HUMAN & (P06576) ATP synthase subunit $\beta$, mitochondrial & 529 & 1 & 7 & 2.06719342 \\
\hline 164 & ADT1_HUMAN & (P12235) ADP/ATP translocase 1 & 298 & 0 & 4 & 2.26131991 \\
\hline 165 & H2A1_HUMAN & (P0C0S8) Histone H2A type 1 & 130 & 0 & 4 & 2.26131991 \\
\hline 166 & RS6_HUMAN & (P62753) 40S ribosomal protein S6 & 249 & 0 & 4 & 2.26131991 \\
\hline 167 & H2B1B_HUMAN & (P33778) Histone H2B type 1-B & 126 & 0 & 4 & 2.26131991 \\
\hline 168 & FLNA_HUMAN & (P21333) Filamin-A & 2647 & 1 & 9 & 2.38204237 \\
\hline 169 & H2B1M_HUMAN & (Q99879) Histone H2B type 1-M & 126 & 0 & 6 & 2.72867159 \\
\hline 170 & H2AX_HUMAN & (P16104) Histone H2A.x & 143 & 0 & 7 & 2.9159295 \\
\hline 171 & H2A1B_HUMAN & (P04908) Histone H2A type 1-B/E & 130 & 0 & 9 & 3.23077846 \\
\hline 172 & H2A1A_HUMAN & (Q96QV6) Histone H2A type 1-A & 131 & 0 & 9 & 3.23077846 \\
\hline 173 & H2B1C_HUMAN & (P62807) Histone H2B type 1-C/E/F/G/I & 126 & 0 & 11 & 3.48962935 \\
\hline 174 & ACTA_HUMAN & (P62736) Actin, aortic smooth muscle & 377 & 0 & 15 & 3.90067941 \\
\hline
\end{tabular}

The expression levels of the 174 proteins were altered more than 2-fold as a result of lumican upregulation.

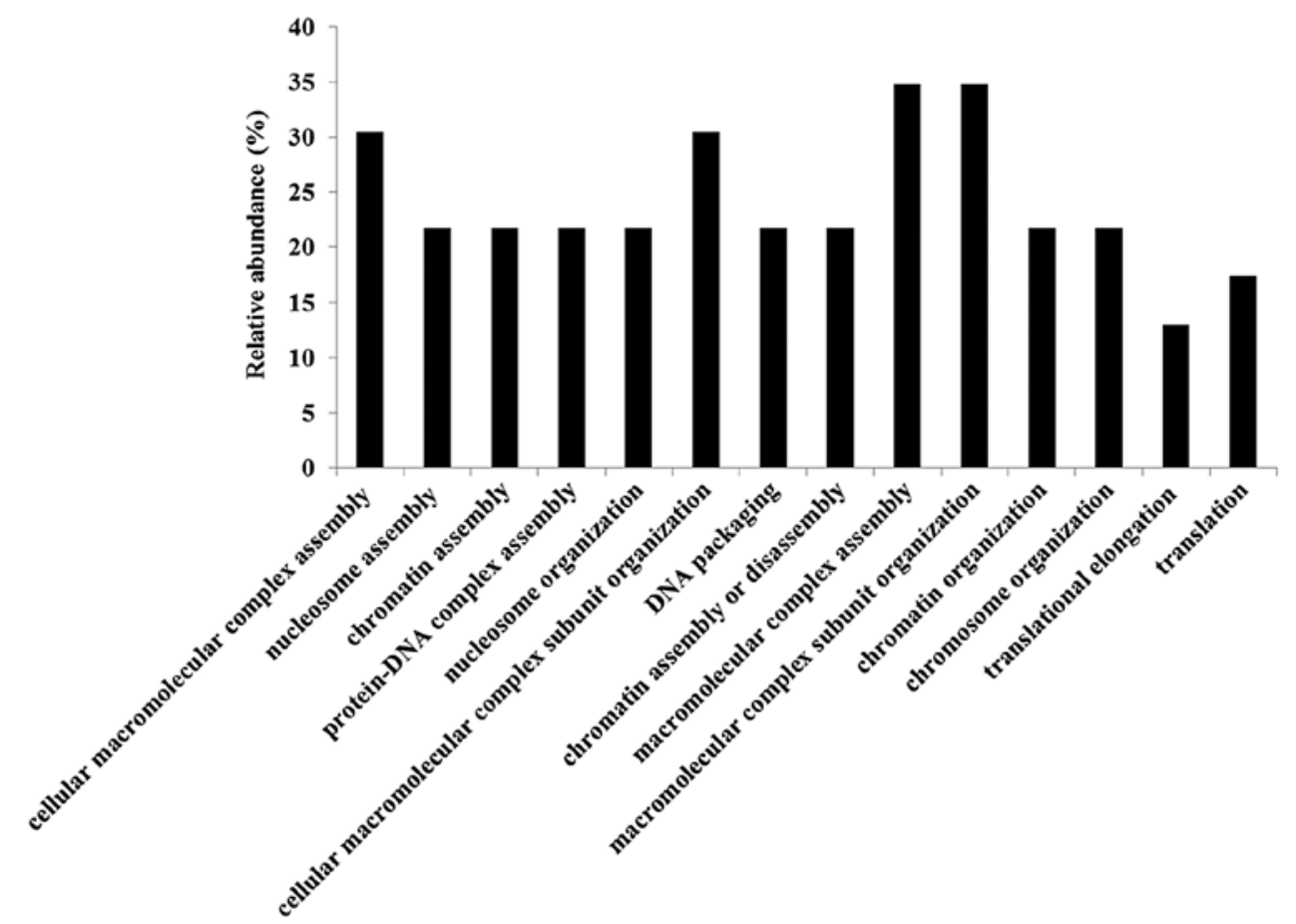

Figure 4. Analysis of identified proteins in the gene ontology biological process category. Only significant categories $(\mathrm{P}<0.05)$ are shown. 
Table II. Differentially expressed proteins in lumican downregulated PANC-1 cells.

\begin{tabular}{|c|c|c|c|c|c|c|}
\hline \multirow[b]{2}{*}{ No. } & \multirow[b]{2}{*}{ ID } & \multirow[b]{2}{*}{ Accession no. and description } & \multirow[b]{2}{*}{$\begin{array}{l}\text { No. of } \\
\text { amino acids }\end{array}$} & \multicolumn{3}{|c|}{ Spectral counting } \\
\hline & & & & $\mathrm{NC}$ & siLum & $\begin{array}{l}\text { Fold-change } \\
\quad \text { (Rsc) }\end{array}$ \\
\hline 1 & ACTG_HUMAN & (P63261) Actin, cytoplasmic 2 & 375 & 19 & 0 & -4.1933172 \\
\hline 2 & H2B1D_HUMAN & (P58876) Histone H2B type 1-D & 126 & 7 & 0 & -2.8944219 \\
\hline 3 & H2A2A_HUMAN & (Q6FI13) Histone H2A type 2-A & 130 & 4 & 0 & -2.2414896 \\
\hline 4 & HNRPU_HUMAN & (Q00839) Heterogeneous nuclear ribonucleoprotein U & 825 & 3 & 0 & -1.9363502 \\
\hline 5 & H2B1M_HUMAN & (Q99879) Histone H2B type 1-M & 126 & 3 & 0 & -1.9363502 \\
\hline 6 & KRT81_HUMAN & (Q14533) Keratin, type II cuticular Hb1 & 505 & 3 & 0 & -1.9363502 \\
\hline 7 & RL10_HUMAN & (P27635) 60S ribosomal protein L10 & 214 & 3 & 0 & -1.9363502 \\
\hline 8 & K2C6B_HUMAN & (P04259) Keratin, type II cytoskeletal 6B & 564 & 6 & 1 & -1.8595343 \\
\hline 9 & CAPZB_HUMAN & (P47756) F-actin-capping protein subunit $\beta$ & 277 & 2 & 0 & -1.5490424 \\
\hline 10 & FUBP2_HUMAN & (Q92945) Far upstream element-binding protein 2 & 711 & 2 & 0 & -1.5490424 \\
\hline 11 & IPO7_HUMAN & (O95373) Importin-7 & 1038 & 2 & 0 & -1.5490424 \\
\hline 12 & K2C6C_HUMAN & (P48668) Keratin, type II cytoskeletal 6C & 564 & 2 & 0 & -1.5490424 \\
\hline 13 & ML12A_HUMAN & (P19105) Myosin regulatory light chain 12A & 171 & 2 & 0 & -1.5490424 \\
\hline 14 & NUCB1_HUMAN & (Q02818) Nucleobindin-1 & 461 & 2 & 0 & -1.5490424 \\
\hline 15 & EF1B_HUMAN & (P24534) Elongation factor $1-\beta$ & 225 & 2 & 0 & -1.5490424 \\
\hline 16 & NDKA_HUMAN & (P15531) Nucleoside diphosphate kinase A & 152 & 2 & 0 & -1.5490424 \\
\hline 17 & VINC_HUMAN & (P18206) Vinculin & 1134 & 7 & 2 & -1.5155258 \\
\hline 18 & PDIA3_HUMAN & (P30101) Protein disulfide-isomerase A3 & 505 & 4 & 1 & -1.3933005 \\
\hline 19 & K2C5_HUMAN & (P13647) Keratin, type II cytoskeletal 5 & 590 & 8 & 3 & -1.2936552 \\
\hline 20 & K1C19_HUMAN & (P08727) Keratin, type I cytoskeletal 19 & 400 & 11 & 5 & -1.1429912 \\
\hline 21 & ECH1_HUMAN & $(\mathrm{Q} 13011) \delta(3,5)-\delta(2,4)$-dienoyl-CoA isomerase, mitochondrial & 328 & 5 & 2 & -1.1144173 \\
\hline 22 & PAIRB_HUMAN & (Q8NC51) Plasminogen activator inhibitor 1 RNA-binding protein & 408 & 5 & 2 & -1.1144173 \\
\hline 23 & RS3_HUMAN & (P23396) 40S ribosomal protein $\mathrm{S} 3$ & 243 & 3 & 1 & -1.0881611 \\
\hline 24 & CRIP1_HUMAN & (P50238) Cysteine-rich protein 1 & 77 & 3 & 1 & -1.0881611 \\
\hline 25 & RS28_HUMAN & (P62857) 40S ribosomal protein S28 & 69 & 3 & 1 & -1.0881611 \\
\hline 26 & RS13_HUMAN & (P62277) 40S ribosomal protein S13 & 151 & 3 & 1 & -1.0881611 \\
\hline 27 & RS27A_HUMAN & (P62979) Ubiquitin-40S ribosomal protein S27a & 156 & 3 & 1 & -1.0881611 \\
\hline 28 & CAPG_HUMAN & (P40121) Macrophage-capping protein & 348 & 1 & 0 & -1.0182433 \\
\hline 29 & CDC42_HUMAN & (P60953) Cell division control protein 42 homolog & 191 & 1 & 0 & -1.0182433 \\
\hline 30 & CX6B1_HUMAN & (P14854) Cytochrome $c$ oxidase subunit 6B1 & 86 & 1 & 0 & -1.0182433 \\
\hline 31 & GDIA_HUMAN & (P31150) Rab GDP dissociation inhibitor $\alpha$ & 447 & 1 & 0 & -1.0182433 \\
\hline 32 & IQGA1_HUMAN & (P46940) Ras GTPase-activating-like protein IQGAP1 & 1657 & 1 & 0 & -1.0182433 \\
\hline 33 & RL12_HUMAN & (P30050) 60S ribosomal protein L12 & 165 & 1 & 0 & -1.0182433 \\
\hline 34 & RL35A_HUMAN & (P18077) 60S ribosomal protein $\mathrm{L} 35 \mathrm{a}$ & 110 & 1 & 0 & -1.0182433 \\
\hline 35 & SQSTM_HUMAN & (Q13501) Sequestosome-1 & 440 & 1 & 0 & -1.0182433 \\
\hline 36 & RL10L_HUMAN & (Q96L21) 60S ribosomal protein L10-like & 214 & 1 & 0 & -1.0182433 \\
\hline 37 & RS14_HUMAN & (P62263) 40S ribosomal protein $\mathrm{S} 14$ & 151 & 1 & 0 & -1.0182433 \\
\hline 38 & AGR3_HUMAN & (Q8TD06) Anterior gradient protein 3 homolog & 166 & 1 & 0 & -1.0182433 \\
\hline 39 & ALMS1_HUMAN & (Q8TCU4) Alstrom syndrome protein 1 & 4167 & 1 & 0 & -1.0182433 \\
\hline 40 & AP3D1_HUMAN & (O14617) AP-3 complex subunit $\delta-1$ & 1153 & 1 & 0 & -1.0182433 \\
\hline 41 & BI2L2_HUMAN & $\begin{array}{l}\text { (Q6UXY1) Brain-specific angiogenesis inhibitor 1-associated } \\
\text { protein 2-like protein } 2\end{array}$ & 529 & 1 & 0 & -1.0182433 \\
\hline 42 & CH041_HUMAN & (Q6NXR4) Uncharacterized protein C8orf41 & 508 & 1 & 0 & -1.0182433 \\
\hline 43 & CORO7_HUMAN & (P57737) Coronin-7 & 925 & 1 & 0 & -1.0182433 \\
\hline 44 & CSPG4_HUMAN & (Q6UVK1) Chondroitin sulfate proteoglycan 4 & 2322 & 1 & 0 & -1.0182433 \\
\hline 45 & CXL14_HUMAN & (O95715) C-X-C motif chemokine 14 & 111 & 1 & 0 & -1.0182433 \\
\hline 46 & DDX17_HUMAN & (Q92841) Probable ATP-dependent RNA helicase DDX17 & 650 & 1 & 0 & -1.0182433 \\
\hline 47 & DNJB1_HUMAN & (P25685) DnaJ homolog subfamily B member 1 & 340 & 1 & 0 & -1.0182433 \\
\hline 48 & EIF3C_HUMAN & (Q99613) Eukaryotic translation initiation factor 3 subunit C & 913 & 1 & 0 & -1.0182433 \\
\hline 49 & FER_HUMAN & (P16591) Tyrosine-protein kinase Fer & 822 & 1 & 0 & -1.0182433 \\
\hline
\end{tabular}


Table II. Continued.

\begin{tabular}{|c|c|c|c|c|c|c|}
\hline \multirow[b]{2}{*}{ No. } & \multirow[b]{2}{*}{ ID } & \multirow[b]{2}{*}{ Accession no. and description } & \multirow[b]{2}{*}{$\begin{array}{c}\text { No. of } \\
\text { amino acids }\end{array}$} & \multicolumn{3}{|c|}{ Spectral counting } \\
\hline & & & & $\mathrm{NC}$ & siLum & $\begin{array}{l}\text { Fold-change } \\
\quad \text { (Rsc) }\end{array}$ \\
\hline 50 & GELS_HUMAN & (P06396) Gelsolin & 782 & 1 & 0 & -1.0182433 \\
\hline 51 & INSRR_HUMAN & (P14616) Insulin receptor-related protein & 1297 & 1 & 0 & -1.0182433 \\
\hline 52 & KRT85_HUMAN & (P78386) Keratin, type II cuticular Hb5 & 507 & 1 & 0 & -1.0182433 \\
\hline 53 & MT1X_HUMAN & (P80297) MT-1X & 61 & 1 & 0 & -1.0182433 \\
\hline 54 & NALP6_HUMAN & (P59044) NACHT, LRR and PYD domains-containing protein 6 & 892 & 1 & 0 & -1.0182433 \\
\hline 55 & PLEC_HUMAN & (Q15149) Plectin & 4684 & 1 & 0 & -1.0182433 \\
\hline 56 & PRS8_HUMAN & (P62195) 26S protease regulatory subunit 8 & 406 & 1 & 0 & -1.0182433 \\
\hline 57 & PUR2_HUMAN & (P22102) Trifunctional purine biosynthetic protein adenosine- 3 & 1010 & 1 & 0 & -1.0182433 \\
\hline 58 & RFX6_HUMAN & (Q8HWS3) DNA-binding protein RFX6 & 928 & 1 & 0 & -1.0182433 \\
\hline 59 & RS17_HUMAN & (P08708) 40S ribosomal protein $\mathrm{S} 17$ & 135 & 1 & 0 & -1.0182433 \\
\hline 60 & RUNX1_HUMAN & (Q01196) Runt-related transcription factor 1 & 453 & 1 & 0 & -1.0182433 \\
\hline 61 & SEPT9_HUMAN & (Q9UHD8) Septin-9 & 586 & 1 & 0 & -1.0182433 \\
\hline 62 & SRSF4_HUMAN & (Q08170) Serine/arginine-rich splicing factor 4 & 494 & 1 & 0 & -1.0182433 \\
\hline 63 & SUMO3_HUMAN & (P55854) Small ubiquitin-related modifier 3 & 103 & 1 & 0 & -1.0182433 \\
\hline 64 & TIM13_HUMAN & $\begin{array}{l}\text { (Q9Y5L4) Mitochondrial import inner membrane } \\
\text { translocase subunit Tim13 }\end{array}$ & 95 & 1 & 0 & -1.0182433 \\
\hline 65 & UGDH_HUMAN & (O60701) UDP-glucose 6-dehydrogenase & 494 & 1 & 0 & -1.0182433 \\
\hline 66 & WDHD1_HUMAN & (O75717) WD repeat and HMG-box DNA-binding protein 1 & 1129 & 1 & 0 & -1.0182433 \\
\hline 67 & ZZEF1_HUMAN & $\begin{array}{l}\text { (O43149) Zinc finger ZZ-type and EF-hand } \\
\text { domain-containing protein } 1\end{array}$ & 2961 & 1 & 0 & -1.0182433 \\
\hline 68 & RL22_HUMAN & (P35268) 60S ribosomal protein $\mathrm{L} 22$ & 128 & 1 & 0 & -1.0182433 \\
\hline 69 & BASP1_HUMAN & (P80723) Brain acid soluble protein 1 & 227 & 1 & 0 & -1.0182433 \\
\hline 70 & SPSY_HUMAN & (P52788) Spermine synthase & 366 & 1 & 0 & -1.0182433 \\
\hline 71 & RS25_HUMAN & (P62851) 40S ribosomal protein $\mathrm{S} 25$ & 125 & 1 & 0 & -1.0182433 \\
\hline 72 & RS9_HUMAN & (P46781) 40S ribosomal protein S9 & 194 & 1 & 0 & -1.0182433 \\
\hline 73 & HIP1R_HUMAN & (O75146) Huntingtin-interacting protein 1-related protein & 1068 & 1 & 0 & -1.0182433 \\
\hline 74 & RL15_HUMAN & (P61313) 60S ribosomal protein L15 & 204 & 1 & 0 & -1.0182433 \\
\hline 75 & G6PI_HUMAN & (P06744) Glucose-6-phosphate isomerase & 558 & 1 & 0 & -1.0182433 \\
\hline 76 & TERA_HUMAN & (P55072) Transitional endoplasmic reticulum ATPase & 806 & 1 & 4 & 1.05291534 \\
\hline 77 & RS5_HUMAN & (P46782) 40S ribosomal protein S5 & 204 & 1 & 4 & 1.05291534 \\
\hline 78 & PCBP3_HUMAN & (P57721) Poly(rC)-binding protein 3 & 371 & 1 & 4 & 1.05291534 \\
\hline 79 & K2C74_HUMAN & (Q7RTS7) Keratin, type II cytoskeletal 74 & 529 & 4 & 11 & 1.0534109 \\
\hline 80 & CH60_HUMAN & (P10809) $60 \mathrm{kDa}$ heat shock protein, mitochondrial & 573 & 7 & 20 & 1.19690092 \\
\hline 81 & RAN_HUMAN & (P62826) GTP-binding nuclear protein Ran & 216 & 0 & 2 & 1.20893401 \\
\hline 82 & ADT2_HUMAN & (P05141) ADP/ATP translocase 2 & 298 & 0 & 2 & 1.20893401 \\
\hline 83 & CAZA1_HUMAN & (P52907) F-actin-capping protein subunit $\alpha-1$ & 286 & 0 & 2 & 1.20893401 \\
\hline 84 & G6PD_HUMAN & (P11413) Glucose-6-phosphate 1-dehydrogenase & 515 & 0 & 2 & 1.20893401 \\
\hline 85 & H2AV_HUMAN & (Q71UI9) Histone H2A.V & 128 & 0 & 2 & 1.20893401 \\
\hline 86 & H2B1H_HUMAN & (Q93079) Histone H2B type 1-H & 126 & 0 & 2 & 1.20893401 \\
\hline 87 & H2B1J_HUMAN & (P06899) Histone H2B type 1-J & 126 & 0 & 2 & 1.20893401 \\
\hline 88 & H2B1K_HUMAN & (O60814) Histone H2B type 1-K & 126 & 0 & 2 & 1.20893401 \\
\hline 89 & HCD2_HUMAN & (Q99714) 3-hydroxyacyl-CoA dehydrogenase type-2 & 261 & 0 & 2 & 1.20893401 \\
\hline 90 & MT1A_HUMAN & (P04731) Metallothionein-1A & 61 & 0 & 2 & 1.20893401 \\
\hline 91 & RL18A_HUMAN & (Q02543) 60S ribosomal protein L18a & 176 & 0 & 2 & 1.20893401 \\
\hline 92 & RL21_HUMAN & (P46778) 60S ribosomal protein $\mathrm{L} 21$ & 160 & 0 & 2 & 1.20893401 \\
\hline 93 & RS7_HUMAN & (P62081) 40S ribosomal protein S7 & 194 & 0 & 2 & 1.20893401 \\
\hline 94 & SPT6H_HUMAN & (Q7KZ85) Transcription elongation factor SPT6 & 1726 & 0 & 2 & 1.20893401 \\
\hline 95 & SRP14_HUMAN & (P37108) Signal recognition particle $14 \mathrm{kDa}$ protein & 136 & 0 & 2 & 1.20893401 \\
\hline 96 & TBA4B_HUMAN & (Q9H853) Putative tubulin-like protein $\alpha-4 B$ & 241 & 0 & 2 & 1.20893401 \\
\hline 97 & TCTP_HUMAN & (P13693) Translationally-controlled tumor protein & 172 & 0 & 2 & 1.20893401 \\
\hline
\end{tabular}


Table II. Continued.

\begin{tabular}{|c|c|c|c|c|c|c|}
\hline \multirow[b]{2}{*}{ No. } & \multirow[b]{2}{*}{ ID } & \multirow[b]{2}{*}{ Accession no. and description } & \multirow[b]{2}{*}{$\begin{array}{c}\text { No. of } \\
\text { amino acids }\end{array}$} & \multicolumn{3}{|c|}{ Spectral counting } \\
\hline & & & & $\mathrm{NC}$ & siLum & $\begin{array}{l}\text { Fold-change } \\
\text { (Rsc) }\end{array}$ \\
\hline 98 & UBB_HUMAN & (P0CG47) Polyubiquitin-B & 229 & 0 & 2 & 1.20893401 \\
\hline 99 & RL19_HUMAN & (P84098) 60S ribosomal protein L19 & 196 & 0 & 2 & 1.20893401 \\
\hline 100 & FKB1A_HUMAN & (P62942) Peptidyl-prolyl cis-trans isomerase FKBP1A & 108 & 0 & 2 & 1.20893401 \\
\hline 101 & MDHM_HUMAN & (P40926) Malate dehydrogenase, mitochondrial & 338 & 0 & 2 & 1.20893401 \\
\hline 102 & NDE1_HUMAN & (Q9NXR1) Nuclear distribution protein nudE homolog 1 & 346 & 0 & 2 & 1.20893401 \\
\hline 103 & PSA5_HUMAN & (P28066) Proteasome subunit $\alpha$ type-5 & 241 & 0 & 2 & 1.20893401 \\
\hline 104 & H2B1B_HUMAN & (P33778) Histone H2B type 1-B & 126 & 0 & 2 & 1.20893401 \\
\hline 105 & HNRH2_HUMAN & (P55795) Heterogeneous nuclear ribonucleoprotein $\mathrm{H} 2$ & 449 & 1 & 5 & 1.30464663 \\
\hline 106 & K2C1_HUMAN & (P04264) Keratin, type II cytoskeletal 1 & 644 & 2 & 8 & 1.34002273 \\
\hline 107 & K1C9_HUMAN & (P35527) Keratin, type I cytoskeletal 9 & 623 & 0 & 3 & 1.59614949 \\
\hline 108 & RLA0L_HUMAN & (Q8NHW5) 60S acidic ribosomal protein P0-like & 317 & 0 & 3 & 1.59614949 \\
\hline 109 & H2A1B_HUMAN & (P04908) Histone H2A type 1-B/E & 130 & 0 & 3 & 1.59614949 \\
\hline 110 & SRC8_HUMAN & (Q14247) Src substrate cortactin & 550 & 0 & 3 & 1.59614949 \\
\hline 111 & UBA1_HUMAN & (P22314) Ubiquitin-like modifier-activating enzyme 1 & 1058 & 0 & 3 & 1.59614949 \\
\hline 112 & H2A1H_HUMAN & (Q96KK5) Histone H2A type 1-H & 128 & 0 & 3 & 1.59614949 \\
\hline 113 & H2A2B_HUMAN & (Q8IUE6) Histone H2A type 2-B & 130 & 0 & 3 & 1.59614949 \\
\hline 114 & HN1_HUMAN & (Q9UK76) Hematological and neurological expressed 1 protein & 154 & 0 & 3 & 1.59614949 \\
\hline 115 & HNRPK_HUMAN & (P61978) Heterogeneous nuclear ribonucleoprotein K & 463 & 0 & 3 & 1.59614949 \\
\hline 116 & K1C14_HUMAN & (P02533) Keratin, type I cytoskeletal 14 & 472 & 0 & 3 & 1.59614949 \\
\hline 117 & K22O_HUMAN & (Q01546) Keratin, type II cytoskeletal 2 oral & 638 & 0 & 3 & 1.59614949 \\
\hline 118 & K6PP_HUMAN & (Q01813) 6-phosphofructokinase type C & 784 & 0 & 3 & 1.59614949 \\
\hline 119 & POTEJ_HUMAN & (POCG39) POTE ankyrin domain family member $\mathrm{J}$ & 1038 & 0 & 3 & 1.59614949 \\
\hline 120 & RADI_HUMAN & (P35241) Radixin & 583 & 0 & 3 & 1.59614949 \\
\hline 121 & HS904_HUMAN & (Q58FG1) Putative heat shock protein HSP 90- $\alpha$ A4 & 418 & 2 & 10 & 1.62280828 \\
\hline 122 & PROF1_HUMAN & (P07737) Profilin-1 & 140 & 3 & 14 & 1.67515744 \\
\hline 123 & H90B3_HUMAN & (Q58FF7) Putative heat shock protein HSP 90- $\beta-3$ & 597 & 1 & 7 & 1.70556987 \\
\hline 124 & TBB2A_HUMAN & (Q13885) Tubulin $\beta-2 A$ chain & 445 & 7 & 33 & 1.88806959 \\
\hline 125 & TIM50_HUMAN & $\begin{array}{l}\text { (Q3ZCQ8) Mitochondrial import inner membrane } \\
\text { translocase subunit TIM50 }\end{array}$ & 353 & 0 & 4 & 1.90119651 \\
\hline 126 & RL4_HUMAN & (P36578) 60S ribosomal protein L4 & 427 & 0 & 4 & 1.90119651 \\
\hline 127 & H2A1C_HUMAN & (Q93077) Histone H2A type 1-C & 130 & 0 & 4 & 1.90119651 \\
\hline 128 & K2C6A_HUMAN & (P02538) Keratin, type II cytoskeletal 6A & 564 & 0 & 4 & 1.90119651 \\
\hline 129 & NDK8_HUMAN & (O60361) Putative nucleoside diphosphate kinase & 137 & 0 & 4 & 1.90119651 \\
\hline 130 & TKT_HUMAN & (P29401) Transketolase & 623 & 0 & 4 & 1.90119651 \\
\hline 131 & H2B1O_HUMAN & (P23527) Histone H2B type 1-O & 126 & 0 & 5 & 2.15292781 \\
\hline 132 & H2B2F_HUMAN & (Q5QNW6) Histone H2B type 2-F & 126 & 0 & 5 & 2.15292781 \\
\hline 133 & ANXA5_HUMAN & (P08758) Annexin A5 & 320 & 0 & 6 & 2.36724523 \\
\hline 134 & H2A2C_HUMAN & (Q16777) Histone H2A type 2-C & 129 & 0 & 6 & 2.36724523 \\
\hline 135 & H2B1L_HUMAN & (Q99880) Histone H2B type 1-L & 126 & 0 & 7 & 2.55385105 \\
\hline 136 & HSP76_HUMAN & (P17066) Heat shock $70 \mathrm{kDa}$ protein 6 & 643 & 0 & 8 & 2.71910308 \\
\hline 137 & TBA3E_HUMAN & (Q6PEY2) Tubulin $\alpha-3 E$ chain & 450 & 0 & 8 & 2.71910308 \\
\hline 138 & TBA3C_HUMAN & (Q13748) Tubulin $\alpha-3 \mathrm{C} / \mathrm{D}$ chain & 450 & 0 & 9 & 2.86739459 \\
\hline 139 & TBA4A_HUMAN & (P68366) Tubulin $\alpha-4 \mathrm{~A}$ chain & 448 & 0 & 14 & 3.44154556 \\
\hline 140 & TBA1A_HUMAN & (Q71U36) Tubulin $\alpha-1 \mathrm{~A}$ chain & 451 & 0 & 14 & 3.44154556 \\
\hline 141 & TBB8_HUMAN & (Q3ZCM7) Tubulin $\beta-8$ chain & 444 & 0 & 16 & 3.61971953 \\
\hline 142 & ACTC_HUMAN & (P68032) Actin, $\alpha$ cardiac muscle 1 & 377 & 0 & 21 & 3.98789716 \\
\hline 143 & ACTS_HUMAN & (P68133) Actin, $\alpha$ skeletal muscle & 377 & 0 & 42 & 4.95088405 \\
\hline
\end{tabular}

The expression levels of the 143 proteins were altered more than 2-fold as a result of lumican downregulation. 
Table III. Correlation between lumican expression level and identified protein expression level.

Fold-change (Rsc)

ID

Accession no. and description

\begin{tabular}{cc}
\hline $\begin{array}{c}\text { Lumican } \\
\text { upregulation }\end{array}$ & $\begin{array}{c}\text { Lumican } \\
\text { downregulation }\end{array}$
\end{tabular}

ACTC_HUMAN

TBB2A_HUMAN

H2B1H_HUMAN

HS904_HUMAN

TBA4A_HUMAN

H2B1O_HUMAN

ANXA5_HUMAN

H2A1H_HUMAN

HNRPK_HUMAN

K22O_HUMAN

K1C14_HUMAN

H2B1J_HUMAN

MDHM_HUMAN

NDK8_HUMAN

HIP1R_HUMAN

RL22_HUMAN

SPSY_HUMAN

RL10L_HUMAN

RL12_HUMAN

RS13_HUMAN

PAIRB_HUMAN

IQGA1_HUMAN

MT1X_HUMAN

H2B1M_HUMAN
(P68032) Actin, $\alpha$ cardiac muscle 1

(Q13885) Tubulin $\beta$-2A chain

(Q93079) Histone H2B type 1-H

(Q58FG1) Putative heat shock protein HSP 90- $\alpha$ A4

(P68366) Tubulin $\alpha-4 A$ chain

(P23527) Histone H2B type 1-O

(P08758) Annexin A5

(Q96KK5) Histone H2A type 1-H

(P61978) Heterogeneous nuclear ribonucleoprotein K

(Q01546) Keratin, type II cytoskeletal 2 oral

(P02533) Keratin, type I cytoskeletal 14

(P06899) Histone H2B type 1-J

(P40926) Malate dehydrogenase, mitochondrial

(O60361) Putative nucleoside diphosphate kinase

(O75146) Huntingtin-interacting protein 1-related protein

(P35268) 60S ribosomal protein L22

(P52788) Spermine synthase

(Q96L21) 60S ribosomal protein L10-like

(P30050) 60S ribosomal protein L12

(P62277) 40S ribosomal protein S13

(Q8NC51) Plasminogen activator inhibitor 1 RNA-binding protein

(P46940) Ras GTPase-activating-like protein IQGAP1

(P80297) Metallothionein-1X

(Q99879) Histone H2B type 1-M
$-3.770661694$

$-2.989773612$

$-2.854729916$

$-2.705889054$

$-2.705889054$

$-1.885788034$

$-1.580193134$

$-1.580193134$

$-1.580193134$

$-1.580193134$

$-1.504094641$

$-1.192430072$

$-1.192430072$

$-1.192430072$

1.036399032

1.036399032

1.036399032

1.106885931

1.106885931

1.106885931

1.348681223

1.567756075

1.955622017

2.728671586
3.987897158

1.888069587

1.208934009

1.622808285

3.441545557

2.152927808

2.367245226

1.596149489

1.596149489

1.596149489

1.596149489

1.208934009

1.208934009

1.901196513

$-1.018243251$

$-1.018243251$

$-1.018243251$

$-1.018243251$

$-1.018243251$

$-1.088161097$

$-1.114417304$

$-1.018243251$

$-1.018243251$

$-1.936350191$

Twenty-four proteins showed correlation between lumican expression level and their expression level.

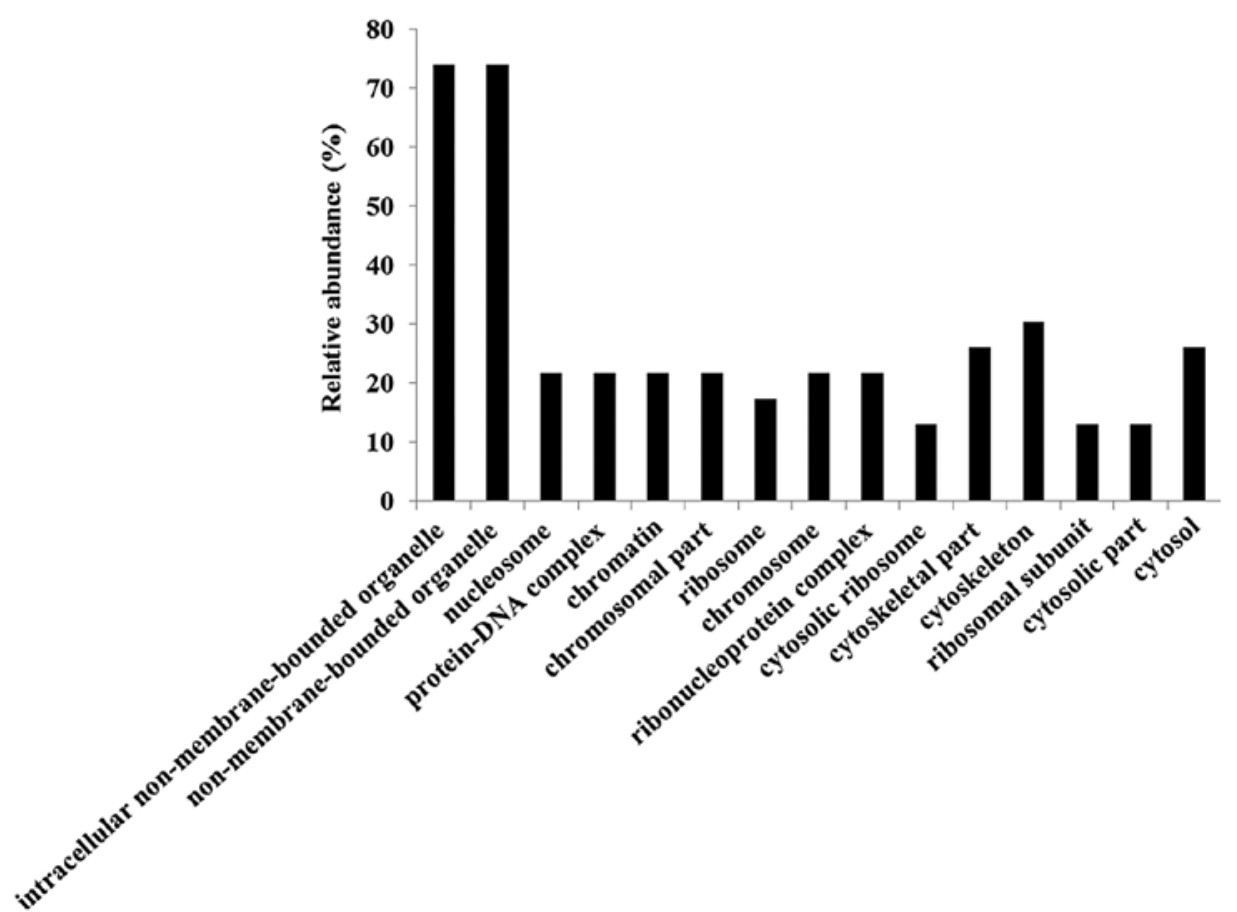

Figure 5. Analysis of identified proteins in the gene ontology cellular component. Only significant categories $(\mathrm{P}<0.05)$ are shown. 
To examine the role of these candidate proteins in the effect of lumican on cell growth and invasion, we performed a functional classification of the candidate proteins by GO analysis. Although the GO terms for molecular function, biological processes, and cellular components were examined, we focused on molecular function. The molecular functions of candidate proteins were mainly classified in the 'structural molecule activity' category. Since structural molecule activity proteins contribute to the formation of complexes within or outside of the cell, such candidate proteins may be related to cell invasion regulated by lumican.

Annexin A5 expression may be regulated by lumican since Annexin A5 expression was negatively correlated with the lumican expression level. Annexin A5, also known as Annexin V, is widely known as a marker of early stage apoptosis $(36,37)$. We previously demonstrated that the PDAC cell line secretes $70-\mathrm{kDa}$ glycosylated lumican and that this secreted lumican stimulates cell growth (28). Thus, the induction of cell growth by lumican may be related to an inhibition of apoptosis through Annexin A5 expression. However, previous reports suggest that lumican plays an important role in apoptosis induction $(22,38-40)$. This discrepancy may be derived from the differences between glycosylated lumican secreted from the PDAC cell line and other cells.

Furthermore, MT-1X expression levels positively correlated with the lumican expression level. MT family proteins are encoded by 10 functional isoforms (MT-1A, MT-1B, MT-1E, MT-1F, MT-1G, MT-1H, MT-1X, MT-2A, MT-3 and MT-4), and seven non-functional isoforms (MT-1C, MT-1D, MT-1I, MT-1J, MT-1K, MT-L and MT-2B). MT family proteins are involved in essential metal homeostasis, cellular free radical scavenging, cell proliferation, apoptosis, and metal detoxification. MT-1X and MT-2A transcripts were significantly upregulated under hypoxia in human prostate cancer cell lines, and siRNA-MT-2A treatment inhibited cell growth and induction of apoptosis, but an effect of MT-1X on cell growth and apoptosis was not demonstrated (41). Zinc is an abundant metal in the human prostate, and zinc inhibits cell growth and induces apoptosis in human prostate cancer cell lines $(42,43)$. These findings suggest that MT-2A may play an important role in cell growth and apoptosis in prostate cancer through intracellular zinc homeostasis. MT-1X function in cancer cells, particularly PDAC, is not well understood. MT-1X is a known zinc-binding protein, and MT-1X mRNA expression was induced, as well as MT-2A, under hypoxic conditions (41). Thus, MT-1X may inhibit apoptosis as well as MT-2A. Furthermore, Ryu et al (44) suggested that MT-1E could enhance the migration and invasion of human glioma cells by inducing MMP-9 activation. MT-1X may have functions resembling MT-1E, since MMP-9 is a zinc-requiring enzyme, and MT-1X is classified into isoforms such as MT-1E. As mentioned above, it may be postulated that MT-1X plays an important role in cell growth and invasion by lumican. Further study is required to validate the expression levels of these candidate proteins, and to clarify the effect of candidate proteins, including MT-1X, on cell growth and invasion that are affected by lumican.

In conclusion, we identified more than 400 proteins from both lumican upregulated and lumican downregulated cells using global shotgun proteomics. A label-free semi-quanti- tative method based on spectral counting led to 24 candidate proteins whose expression was regulated by lumican. These candidate proteins included apoptosis-related and invasionrelated proteins. Therefore, lumican may be involved in cell growth and invasion by altering the expression of these proteins.

\section{Acknowledgements}

The authors thank K. Teduka and T. Fujii for their technical assistance (Department of Pathology, Integrative Oncological Pathology). The present study was supported by a Grant-in-Aid for Scientific Research from the Japan Society for the Promotion of Science to T.Y. (C, no. 24591019) and Z.N. (C, no. 23590477).

\section{References}

1. Nikitovic D, Katonis P, Tsatsakis A, Karamanos NK and Tzanakakis GN: Lumican, a small leucine-rich proteoglycan. IUBMB Life 60: 818-823, 2008.

2. Iozzo RV: Matrix proteoglycans: from molecular design to cellular function. Annu Rev Biochem 67: 609-652, 1998.

3. Grover J, Chen XN, Korenberg JR and Roughley PJ: The human lumican gene. Organization, chromosomal location, and expression in articular cartilage. J Biol Chem 270: 21942-21949, 1995.

4. Chakravarti S, Stallings RL, SundarRaj N, Cornuet PK and Hassell JR: Primary structure of human lumican (keratan sulfate proteoglycan) and localization of the gene (LUM) to chromosome 12q21.3-q22. Genomics 27: 481-488, 1995.

5. Naito Z: Role of the small leucine-rich proteoglycan (SLRP) family in pathological lesions and cancer cell growth. J Nippon Med Sch 72: 137-145, 2005.

6. Rada JA, Cornuet PK and Hassell JR: Regulation of corneal collagen fibrillogenesis in vitro by corneal proteoglycan (lumican and decorin) core proteins. Exp Eye Res 56: 635-648, 1993.

7. Svensson L, Närlid I and Oldberg A: Fibromodulin and lumican bind to the same region on collagen type I fibrils. FEBS Lett 470: 178-182, 2000.

8. Chakravarti S: Functions of lumican and fibromodulin: lessons from knockout mice. Glycoconj J 19: 287-293, 2002.

9. Vogel KG, Paulsson $M$ and Heinegård D: Specific inhibition of type I and type II collagen fibrillogenesis by the small proteoglycan of tendon. Biochem J 223: 587-597, 1984.

10. Chakravarti S, Magnuson T, Lass JH, Jepsen KJ, LaMantia C and Carroll H: Lumican regulates collagen fibril assembly: skin fragility and corneal opacity in the absence of lumican. J Cell Biol 141: 1277-1286, 1998.

11. Jepsen KJ, Wu F, Peragallo JH, et al: A syndrome of joint laxity and impaired tendon integrity in lumican- and fibromodulindeficient mice. J Biol Chem 277: 35532-35540, 2002.

12. Blochberger TC, Cornuet PK and Hassell JR: Isolation and partial characterization of lumican and decorin from adult chicken corneas. A keratan sulfate-containing isoform of decorin is developmentally regulated. J Biol Chem 267: 20613-20619, 1992.

13. Dolhnikoff M, Morin J, Roughley PJ and Ludwig MS: Expression of lumican in human lungs. Am J Respir Cell Mol Biol 19: 582-587, 1998 .

14. Qin H, Ishiwata T and Asano G: Effects of the extracellular matrix on lumican expression in rat aortic smooth muscle cells in vitro. J Pathol 195: 604-608, 2001.

15. Baba H, Ishiwata T, Takashi E, Xu G and Asano G: Expression and localization of lumican in the ischemic and reperfused rat heart. Jpn Circ J 65: 445-450, 2001.

16. Onda M, Ishiwata $T$, Kawahara $K$, Wang $R$, Naito $Z$ and Sugisaki Y: Expression of lumican in thickened intima and smooth muscle cells in human coronary atherosclerosis. Exp Mol Pathol 72: 142-149, 2002.

17. Ping Lu Y, Ishiwata T and Asano G: Lumican expression in alpha cells of islets in pancreas and pancreatic cancer cells. J Pathol 196: 324-330, 2002.

18. Lu YP, Ishiwata T, Kawahara K, et al: Expression of lumican in human colorectal cancer cells. Pathol Int 52: 519-526, 2002. 
19. Kelemen LE, Couch FJ, Ahmed S, et al: Genetic variation in stromal proteins decorin and lumican with breast cancer: investigations in two case-control studies. Breast Cancer Res 10: R98, 2008.

20. Troup S, Njue C, Kliewer EV, et al: Reduced expression of the small leucine-rich proteoglycans, lumican, and decorin is associated with poor outcome in node-negative invasive breast cancer. Clin Cancer Res 9: 207-214, 2003.

21. Ishiwata T, Cho K, Kawahara K, et al: Role of lumican in cancer cells and adjacent stromal tissues in human pancreatic cancer. Oncol Rep 18: 537-543, 2007.

22. Vuillermoz B, Khoruzhenko A, D'Onofrio MF, et al: The small leucine-rich proteoglycan lumican inhibits melanoma progression. Exp Cell Res 296: 294-306, 2004.

23. Shinji S, Tajiri T, Ishiwata T, Seya T, Tanaka $N$ and Naito Z Different expression levels of lumican in human carcinoid tumor and neuroendocrine cell carcinoma. Int J Oncol 26: 873-880, 2005.

24. Seya T, Tanaka N, Shinji S, et al: Lumican expression in advanced colorectal cancer with nodal metastasis correlates with poor prognosis. Oncol Rep 16: 1225-1230, 2006.

25. Matsuda Y, Yamamoto T, Kudo M, et al: Expression and roles of lumican in lung adenocarcinoma and squamous cell carcinoma. Int J Oncol 33: 1177-1185, 2008

26. Leygue E, Snell L, Dotzlaw H, et al: Expression of lumican in human breast carcinoma. Cancer Res 58: 1348-1352, 1998.

27. Naito Z, Ishiwata T, Kurban G, et al: Expression and accumulation of lumican protein in uterine cervical cancer cells at the periphery of cancer nests. Int J Oncol 20: 943-948, 2002.

28. Yamamoto T, Matsuda Y, Kawahara K, Ishiwata T and Naito Z: Secreted 70kDa lumican stimulates growth and inhibits invasion of human pancreatic cancer. Cancer Lett 320: 31-39, 2012.

29. Bluemlein $\mathrm{K}$ and Ralser $\mathrm{M}$ : Monitoring protein expression in whole-cell extracts by targeted label- and standard-free LC-MS/MS. Nat Protoc 6: 859-869, 2011.

30. Old WM, Meyer-Arendt K, Aveline-Wolf L, et al: Comparison of label-free methods for quantifying human proteins by shotgun proteomics. Mol Cell Proteomics 4: 1487-1502, 2005.

31. Zybailov B, Coleman MK, Florens L and Washburn MP Correlation of relative abundance ratios derived from peptide ion chromatograms and spectrum counting for quantitative proteomic analysis using stable isotope labeling. Analytical chemistry 77: 6218-6224, 2005.
32. Dennis G Jr, Sherman BT, Hosack DA, et al: DAVID: Database for Annotation, Visualization, and Integrated Discovery. Genome Biol 4: P3, 2003.

33. Huang da W, Sherman BT and Lempicki RA: Systematic and integrative analysis of large gene lists using DAVID bioinformatics resources. Nat Protoc 4: 44-57, 2009.

34. Huang da W, Sherman BT and Lempicki RA: Bioinformatics enrichment tools: paths toward the comprehensive functional analysis of large gene lists. Nucleic Acids Res 37: 1-13, 2009.

35. Lundgren DH, Hwang SI, Wu L and Han DK: Role of spectral counting in quantitative proteomics. Expert Rev Proteomics 7: 39-53, 2010

36. Vermes I, Haanen C, Steffens-Nakken $\mathrm{H}$ and Reutelingsperger C A novel assay for apoptosis. Flow cytometric detection of phosphatidylserine expression on early apoptotic cells using fluorescein labelled Annexin V. J Immunol Methods 184: 39-51, 1995.

37. Aubry JP, Blaecke A, Lecoanet-Henchoz S, et al: Annexin V used for measuring apoptosis in the early events of cellular cytotoxicity. Cytometry 37: 197-204, 1999.

38. Vij N, Roberts L, Joyce S and Chakravarti S: Lumican suppresses cell proliferation and aids Fas-Fas ligand mediated apoptosis: implications in the cornea. Exp Eye Res 78: 957-971, 2004.

39. Brezillon S, Venteo L, Ramont L, et al: Expression of lumican, a small leucine-rich proteoglycan with antitumour activity, in human malignant melanoma. Clin Exp Dermatol 32: 405-416, 2007.

40. Williams KE, Fulford LA and Albig AR: Lumican reduces tumor growth via induction of fas-mediated endothelial cell apoptosis. Cancer Microenviron 4: 115-126, 2010.

41. Yamasaki M, Nomura T, Sato F and Mimata H: Metallothionein is up-regulated under hypoxia and promotes the survival of human prostate cancer cells. Oncol Rep 18: 1145-1153, 2007.

42. Liang JY, Liu YY, Zou J, Franklin RB, Costello LC and Feng P: Inhibitory effect of zinc on human prostatic carcinoma cell growth. Prostate 40: 200-207, 1999.

43. Feng P, Li TL, Guan ZX, Franklin RB and Costello LC: Direct effect of zinc on mitochondrial apoptogenesis in prostate cells. Prostate 52: 311-318, 2002.

44. Ryu HH, Jung S, Jung TY, et al: Role of metallothionein $1 \mathrm{E}$ in the migration and invasion of human glioma cell lines. Int $\mathbf{J}$ Oncol 41: 1305-1313, 2012. 